\title{
Efecto del ácido salicílico en la eliminación de PLRV y PVY en plantas de papa
}

\author{
R.A. González Pasayo 1; M. Huarte ${ }^{1}$
}

\begin{abstract}
Resumen
Plántulas de cinco genotipos de Solanum tuberosum y cuatro genotipos de $S$. tarijense infectadas con el Virus $Y$ de la Papa (PVY) y el Virus del Enrollamiento de las Hojas de la Papa (PLRV), multiplicadas de ápices caulinares y cultivadas in vitro en presencia o ausencia de ácido salicílico (AS) $10^{-5}$ molar (M) a $25^{\circ} \mathrm{C}$ durante 30 días fueron evaluadas en su respuesta a la termoterapia $\left(40^{\circ} \mathrm{C} / 8 \mathrm{~h}\right.$ y $32^{\circ}$ $\mathrm{C} / 16 \mathrm{~h}$ durante 30 días). El promedio de la supervivencia de las plántulas de los nueve genotipos infectados cultivados en medio con AS $10^{-5} \mathrm{M}$ fue mayor $(82,2 \%)$ que en las plántulas cultivadas en medio sin AS $(54,4 \%)$. Además, el promedio de plántulas libres de virus obtenido después de la termoterapia fue $\mathbf{8 7 , 3 \%}$ en las plántulas cultivadas con AS y $55,6 \%$ en las plántulas cultivadas en ausencia de dicho compuesto. Finalmente, la eficiencia en la obtención de plántulas sin infección de virus por termoterapia aumentó de $30,6 \%$ al $72,2 \%$ en las plántulas tratadas con AS.
\end{abstract}

Palabras clave adicionales:

Virus, eliminación, termoterapia, in vitro.

Aceptado para publicación: Marzo 28, 2011.

${ }^{1}$ Grupo de Investigación en Papa, Área Agronomía, EEA INTA Balcarce, Ruta Nacional 226 Km 73,5 (B7620ZAA) Balcarce, Argentina. Correo electrónico: rgonzalez@balcarce.inta.gov.ar 


\section{Effect of Salicylic Acid on PLRV and PVY Elimination from Potato Plantlets}

\section{Summary}

Plantlets of five genotypes of Solanum tuberosum and four genotypes of S. tarijense infected with Potato Virus Y (PVY) or Potato Leafroll Virus (PLRV), propagated from stem apical tips and in vitro cultured with or without $10^{-5}$ molar (M) salicylic acid (SA) at $25^{\circ} \mathrm{C}$ for 30 days were evaluated for their response to the thermotherapy $\left(40^{\circ} \mathrm{C} / 8 \mathrm{~h}, 32^{\circ} \mathrm{C} / 16 \mathrm{~h}\right.$, for 30 days). The average of plantlet survival of the nine infected genotypes cultured in medium with SA was higher $(82,2 \%)$ than observed in plantlet cultured in medium without SA $(54,4 \%)$. Furthermore, the average of virus-free plantlets obtained after thermotherapy was $87,3 \%$ in plantlets cultured with $S A$ and $55,6 \%$ in plantlets using medium without SA. Finally, the efficiency of virus-free plantlets obtained by thermotherapy increased from $30,6 \%$ to a $72,2 \%$ in SAtreated plantlets.

Additional key words:

Virus elimination, thermotherapy, in vitro.

\section{Introduc ción}

Las enfermedades causadas por virus pueden provocar reducciones significativas en los rendimientos de los cultivos. Se han identificado alrededor de 40 virus diferentes capaces de infectar a la papa cultivada en distintas regiones del planeta, entre ellos el PLRV, PVY, PVA, PVX, PVS y PVM. En la actualidad, el PVY y el PLRV son considerados los más perjudiciales por su impacto en la producción de papa (Valkonen, 2007). Estos patógenos sistémicos pueden ser perpetuados como resultado de la multiplicación vegetativa utilizada en la producción de plántulas y tubérculos semillas. La producción de plántulas y de tubérculos semillas libres de virus es la forma más eficaz de reducir el efecto perjudicial de las enfermedades provocadas por virus y para ello se requieren métodos de eliminación de dichos patógenos. 
El empleo de altas temperaturas (termoterapia) y compuestos antivirales (quimioterapia) junto con la propagación de las plantas mediante el aislamiento de ápices meristemáticos caulinares 0 segmentos nodales aplicados en forma independiente o combinada han sido los métodos utilizados frecuentemente para la eliminación de virus de plantas de papa en los últimos cuarenta años (Griffiths et al., 1990; Lerch, 1977; MacDonald, 1973; Mellor y Stace-Smith, 1970; Sánchez et al., 1991; Slack, 1980; Zapata et al., 1995). La aplicación de corriente eléctrica a tallos (electroterapia) (Lozoya-Saldaña et al., 1996) y el tratamiento de meristemas con temperatura extremadamente baja (crioterapia) también han sido aplicados en la eliminación viral de plantas de papa en los últimos años (Wang et al., 2006). Estos tratamientos sobre los tejidos infectados alteran la multiplicación y retardan el movimiento del virus en la planta con la consecuente disminución de la concentración viral. El tejido libre de virus se encuentra generalmente en la zona próxima a los meristemas, tanto de las yemas apicales como las yemas axilares. Al ser cortadas estas yemas y luego cultivadas en medios nutritivos se hace posible la obtención de una planta libre del patógeno (Panta y Golmirzaie, 1997). Si bien estos métodos han permitido la obtención de diversos genotipos de papa libres de virus, se han detectado genotipos menos tolerantes al tratamiento térmico o químico, los cuales afectan negativamente la supervivencia de las plantas tratadas y dificultan la obtención de plantas libres de virus (Sánchez et al., 1991). Además, estos métodos requieren un período de 4 a 8 meses e insumos costosos para obtener plantas que puedan ser evaluadas respecto a la presencia o ausencia del virus. Estos motivos dificultan la aplicación eficiente de los métodos mencionados en programas de saneamiento viral. Finalmente, la necesidad de obtener papas silvestres libres de virus para ser conservadas en bancos de germoplasma plantea la utilización de un método efectivo en un gran número de especies de papa.

La respuesta a estreses medioambientales en plantas es activada por el ácido salicílico (AS; ácido 2-hidroxibenzoico) y existen evidencias que indican que el AS actúa como una señal endógena que desencadena la resistencia sistémica adquirida 
incluso aplicado exógenamente en ausencia del estrés (Antoniw y White, 1980; Pennazio et al., 1987; Ward et al., 1991). Se ha observado que el AS induce la tolerancia a altas temperaturas y dicho efecto ha sido aplicado en la eliminación del PVX en plántulas de $S$. tuberosum y se ha demostrado el efecto beneficioso del cultivo de segmentos nodales en presencia de AS en la sobrevivencia de plántulas sometidas a tratamiento térmico y en el número de plantas libres del PVX obtenidas en dicho tratamiento (López-Delgado et al., 2004).

El objetivo de este trabajo fue investigar el efecto del AS en la erradicación de PLRV ó PVY mediante termoterapia utilizando ápices caulinares de plántulas de papa.

\section{Materiales y Métodos}

Los ápices caulinares (2-3 mm de longitud) del tallo de plántulas infectadas con PVY ó PLRV comprendiendo el domo meristemático apical, los primordios foliares y primera hoja provenientes de 5 genotipos de $S$. tuberosum y 4 genotipos de S. tarijense (Tabla 1) se cultivaron asépticamente en cajas Magenta ${ }^{\circledR}$ GA-7 conteniendo en el medio Murashige y Skoog (1962) (MS) con vitaminas (M5519, Phytotechnology Laboratorios) y $3 \%(\mathrm{w} / \mathrm{v})$ de sacarosa, $0.1 \mathrm{mg} / \mathrm{l}$ de ácido giberélico, $20 \mathrm{mg} / \mathrm{l}$ de putrescina, $1 \mathrm{ml} / \mathrm{l}$ de Plant Preservative Mixture, $0.6 \%$ de agar y con $\mathrm{pH}$ : 6.0; con y sin adición de AS $10^{-5}$ $\mathrm{M}$ a $25^{\circ} \mathrm{C}$ durante 30 días (período de inducción). El AS fue agregado al MS antes de la esterilización en una solución stock en etanol. Los ápices caulinares de las plantas obtenidas fueron colocadas en MS con vitaminas ( $\sin$ AS) en cajas Magenta, las cuales se cultivaron a $25^{\circ} \mathrm{C}$ durante $24 \mathrm{~h}$ (período de recuperación del estrés provocado por el corte) (Figura 1). Luego, las cajas fueron sometidas al tratamiento térmico alternado a $40^{\circ} \mathrm{C}$ durante $8 \mathrm{~h}$ y $32^{\circ} \mathrm{C}$ durante $16 \mathrm{~h}$ en una cámara de crecimiento con un fotoperíodo de $16 \mathrm{~h}$ de baja radiación (luz fluorescente fría, $35 \mathrm{~mol} \mathrm{~m} \mathrm{sec}^{-1}, 400-700 \mathrm{~nm}$ ) durante 30 días. De las plántulas sobrevivientes al tratamiento térmico se cortaron los ápices caulinares, los cuales fueron cultivados en tubos (16 x $110 \mathrm{~mm}$ ) con medio MS sin AS durante 20-30 días. De las plántulas obtenidas se separó el ápice caulinar de cada planta, 
los cuales se colocaron en otros tubos con medio MS sin AS donde crecieron las plantas. El nivel de infección viral de PVY y PLRV fue determinado por la técnica de ELISA (Clark y Adams, 1977) utilizando el resto de la planta carente del ápice caulinar.

\section{Tabla 1. Genotipos de papa y vinus detectados en cada genotipo}

\begin{tabular}{llcc}
\hline Genotipo & Especie & PVY & PLRV \\
\hline B 00.607.1 & Solanum tuberosum & & + \\
B 99.558.1 & Solanum tuberosum & & + \\
PO 99.26.1 & Solanum tuberosum & + & \\
304150.8 LB & Solanum tuberosum & + & + \\
304072.6 LB & Solanum tuberosum & + & + \\
OCL 7383.7 & Solanum tarijense & & \\
OCL 7383.10 & Solanum tarijense & & \\
OKA 5632.12 & Solanum tarijense & + & \\
OCL 7383.14 & Solanum tarijense & + & \\
\hline
\end{tabular}

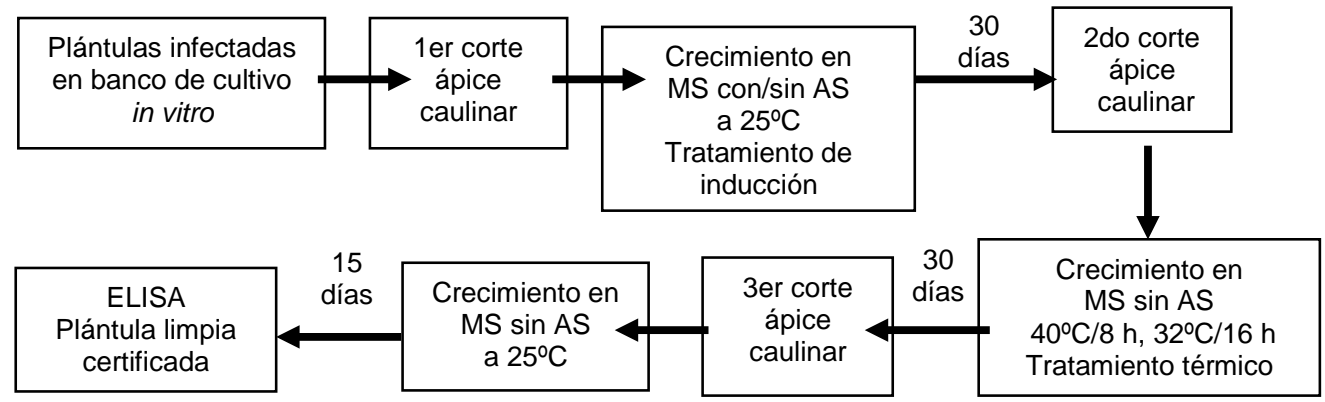

Figura 1. Diagrama del procedimiento experimental 


\section{Resultados y Disc usión}

El promedio de la sobrevivencia a la termoterapia $\left(40^{\circ} \mathrm{C} / 8 \mathrm{~h}\right.$ y $32^{\circ} \mathrm{C} / 16 \mathrm{~h}$ durante 30 días) de las plántulas de los nueve genotipos de $S$. tuberosum y $S$. tarijense infectados con PVY o PLRV cultivados en medio sin AS $10^{-5} \mathrm{M}$ aumentó del 54,4\% al $82,2 \%$ en comparación con el observado en las plántulas cultivadas en medio con AS (Tabla 2). Además, el promedio del porcentaje de plantas libres de virus sometidas a termoterapia aumentó del $55,6 \%$ en las plántulas cultivadas en ausencia de AS al $87,3 \%$ registrado en las plántulas cultivadas con dicho compuesto (Tabla 2). Finalmente, la eficiencia de plantas libres de virus aumentó de $30,6 \%$ al $72,2 \%$ con la aplicación de AS al medio de cultivo antes del tratamiento térmico (Tabla 2). Se observó que la combinación de la termoterapia y la multiplicación de las plántulas mediante el ápice caulinar pudieron erradicar el virus en algunas plantas, el agregado de AS $10^{-5}$ al medio de propagación mejora la supervivencia, el desarrollo general de las plantas sometidas a termoterapia y el consecuente aumento en el porcentaje de plantas saneadas. No se observó diferencia en la eficiencia del saneamiento respecto al genotipo de papa infectada ni al virus erradicado. Algunos de los genotipos utilizados (B 00.607.1, PO 99.26.1, OCL 7383.10, OCL 7383.7), habían sido sometidos previamente a terapia antiviral utilizando el método descripto por Zapata et al. (1995), sin haber logrado su saneamiento. Además, el porcentaje de plantas libres de virus obtenido en el presente estudio es similar o levemente menor a los porcentajes reportados por Wang et al. (2006) en la obtención de plantas libres de PLRV (83-86\%) y PVY (91-95\%) mediante tratamientos criogénicos, dicho porcentaje sumado al corto período de regeneración y a la simpleza del procedimiento convierten al tratamiento aquí descrito en un valiosa herramienta a utilizar en la obtención de plantas libres de virus.

Se ha observado que cuanto menor es el tamaño del explante mayor es la probabilidad de obtener plántulas saneadas y menor es su capacidad de regeneración (Sánchez et al., 1991). Si bien el efecto del tamaño del explante en la eliminación de virus no se estudió en este trabajo, la utilización de ápices caulinares en la multiplicación de las plántulas tratadas reduce la probabilidad de 
la existencia de células vegetales infectadas por el virus respecto a la utilización de esquejes de uno o varios nudos (Griffiths et al., 1990; Zapata et al., 1995) y al mismo tiempo, el ápice caulinar presenta un rápida tasa de regeneración de una planta (20-25 días) respecto a un meristema apical (5-6 meses) (Sánchez et al., 1991).

Tabla 2. Efecto del AS en la supenivencia y en el saneamiento de PLRV o PVY por temoterapia utilizando ápices caulinares de plántulas de 5 genotipos de $S$. tuberosum y 4 genotipos de $S$. tarjense. Se analizaron 10 plantas de cada genotipo. La eficiencia fue calculada multiplicando el \% de supenivencia $x \%$ de plantas saneadas

\begin{tabular}{lcccccc}
\hline & \multicolumn{9}{c}{$\begin{array}{c}\text { \% Plantas } \\
\text { Genotipo }\end{array}$} & $\begin{array}{c}\text { \% Supervivencia } \\
+ \text { AS }^{*}\end{array}$ & -AS & + AS & -AS & \% Eficiencia \\
+AS & -AS \\
\hline B 00.607.1 & 90 & 50 & 89 & 60 & 80 & 30 \\
B 99.558.1 & 80 & 50 & 87 & 40 & 70 & 20 \\
PO 99.26.1 & 90 & 70 & 89 & 71 & 80 & 50 \\
304150.8 LB & 80 & 50 & 100 & 60 & 80 & 30 \\
304072.6 LB & 80 & 40 & 87 & 40 & 70 & 16 \\
OCL 7383.7 & 80 & 60 & 87 & 67 & 70 & 40 \\
OCL 7383.10 & 70 & 50 & 71 & 60 & 50 & 30 \\
OKA 5632.12 & 80 & 50 & 87 & 60 & 70 & 30 \\
OCL 7383.14 & 90 & 70 & 89 & 43 & 80 & 30 \\
\hline Media & 82,22 & 54,44 & 87,33 & 55,66 & 72,22 & 30,66 \\
DS & $\pm 6,28$ & $\pm 9,55$ & $\pm 6,96$ & $\pm 11,00$ & $\pm 9,16$ & $\pm 9,38$ \\
\hline "AS: Ácido Salicílico; DE: Desviación & & & & &
\end{tabular}

La utilización del AS en la eliminación de PVX en combinación con termoterapia en $S$. tuberosum fue reportada por LópezDelgado et al. (2004) pero su utilización no ha sido evaluada en la eliminación de PVY ni PLRV hasta el presente estudio. PVY y PLRV son los virus más perjudiciales del cultivo de papa en la actualidad, en particular en Europa y Sudamérica (Valkonen, 2007). Existen evidencias sobre la reducción de la actividad de la catalasa y el consecuente aumento del nivel de $\mathrm{H}_{2} \mathrm{O}_{2}$ provocado 
por la presencia del AS en el medio de cultivo de las plántulas de papa (López-Delgado et al., 1998, 2004). Ambos efectos estarían involucrados en el aumento de la tolerancia al estrés térmico y en la inhibición de la replicación y la movilidad a distancia del virus en la planta, evitando su diseminación en las partes más jóvenes de la planta como el ápice caulinar. El mencionado efecto sobre la replicación y movilidad a distancia ha sido determinado en la infección de plantas de tabaco por PVX (Naylor et al., 1995) pero no ha sido estudiado en plantas infectadas con PVY o PLRV hasta el presente. Los resultados preliminares obtenidos en este trabajo permiten inferir que el AS cumpliría un rol importante en los sistemas de eliminación viral en papa.

En conclusión, los resultados muestran que el método descrito aumenta la eficiencia del saneamiento al reducir el tiempo de obtención de plántulas sanas a 3-3,5 meses. Además, es de fácil aplicación ya que no requiere de drogas antivirales y se evita su efecto fitotóxico en las plantas a sanear. Por último, no se requiere de instrumental óptico ni de la pericia necesaria para el aislamiento de ápices meristemáticos.

\section{Agradecimientos}

Los autores agradecen a Fernanda Riero y Jorge Baliña por su asistencia técnica en el presente trabajo. El trabajo se realizó gracias al financiamiento del Proyecto CYTED PAPASALUD y del PNFHA 061271 del INTA.

\section{Bibliografía Cítada}

Antoniw, J.F.; White, R.F. 1980. The effect of aspirin and polyacrylic acid on soluble leaf protein and resistance to virus infection in five cultivars of tobacco. Phytopathol. Z. 98:331-341.

Clark, M.F.; Adams, A.H. 1977. Characteristics of the micro plate method of enzyme linked immunosorbent assay for the detection of potato viruses. J. Gen. Virol. 34:475-483. 
Griffiths, H.M.; Slack, S.A.; Dodds, I.H. 1990. Effect of chemical and heat therapy on virus concentrations in in vitro potato plantlets. Can. J. Bot. 68:1515-1521.

Lerch, B. 1977. Inhibition of the biosynthesis of potato virus $X$ by ribavirin. Phytopathology 89:44-49.

López-Delgado, H.; Dat, J.F.; Foyer, C.H.; Scott, I.M. 1998. Induction of thermotolerance in potato microplants by acetylsalicylic acid and $\mathrm{H}_{2} \mathrm{O}_{2}$. J. of Exp. Bot. 49:713-720.

López-Delgado, H.; Mora-Herrera, M.E.; Zavaleta-Mancera, H.A.; Cadena-Hinojosa, M.; Scout, I.M. 2004. Salicylic acid enhances heat tolerant and potato virus $X(P V X)$ elimination during thermotherapy of potato microplants. American Potato J. 81:171-176.

Lozoya-Saldaña, H.; Abello, F.J.; Garcia G. de la R. 1996. Electrotherapy and shoot tip culture eliminate potato virus $\mathrm{X}$ in potatoes. American Potato Journal 73:149-154.

MacDonald, D.M. 1973. Heat treatment and meristem culture as a means of freeing potato varieties from viruses $X$ and $S$. Potato Research 16:263-269.

Mellor, F.C.; Stace-Smith, R. 1970. Virus strain differences in eradication of potato viruses $X$ and S. Phytopathology 60:1587-1590.

Naylor, M.; Murphy, A.M.; Berry, J.O.; Carr, J.P. 1998. Salicylic acid can induce resistance to plant virus movement. MPMI 11:860-868.

Murashige, T.; Skoog, F. 1962. A revised medium for rapid growth and bioassays with tobacco tissue cultures. Physiol Plant 15:473-497.

Panta, A.; Golmirzaie, A. 1997. Cultivo de tejidos para la eliminación de patógenos con fines de producción de semilla de papa. Fasc. 4.2. Manual de Producción de Tubérculos-Semillas de Papa, Centro Internacional de la Papa (CIP), Lima, Perú. 8 p.

Pennazio, S.; Colaracio, D.; Reggero, P.; Lenzi, R. 1987. Effect of salicylate stress on the hypersensitive reaction of asparagus bean to tobacco necrosis virus. Physiol. Mol. Plant Pathol. 30:347-357.

Sánchez, G.E.; Slack, S.A.; Dodds, J.H. 1991. Response of selected Solanum species to virus eradication therapy. American Potato Journal 68:299-315. 
Slack, SA. 1980. Pathogen free plants by meristem tip culture. Plant Disease 64:15-17.

Valkonen, J. 2007. Capítulo 28: Viruses: Economical Losses and Biotechnological Potential. pp 619-641 En: Vreugdenhil, D. (ed.). Potato Biology \& Biotechnology: Advances and Perspectives. Elsevier, Amsterdam, p. 856.

Wang, Q.; Lui, Y.; Xie, Y.; You; M. 2006. Cryotherapy of potato shoot tips for efficient elimination of Potato leaf roll virus (PLRV) and Potato virus Y (PVY). Potato Research 49:119-129.

Ward, E.R.; Uknes, S.J.; Williams, S.C.; Dincher, S.S.; Wiederhold, D.L.; Alexander, D.C.; Ahl-goy, P.; J.P.; Metraux, J.P.; Ryals, J.A. 1991. Coordinate gene activity in response to agents that induce systemic acquired resistance. Plant Cell 3:1085-1094.

Zapata, C.; J.C. Miller, Jr.; Smith R.H. 1995. An in vitro procedure to eradicate potato viruses $\mathrm{X}, \mathrm{Y}$, and $\mathrm{S}$ from Russet Norkotah and two of its strains. In vitro Cell. \& Dev. Biol. - Plant 31:153-159. 